\title{
ACUTE ZINC DEFICIENCY OBSERVED IN CACAO ON CERTAIN SOIL TYPES IN NETHERLANDS NEW GUINEA')
}

\author{
H. SCHROO \\ Head of Soil Department, Agricultural Research Station \\ for Netherlands New Guinea, Manokwari
}

\begin{abstract}
SUMMARY
Acute leaf symptoms of zinc deficiency in young cacao has been observed in the field on two different soil types in' Netherlands New Guinea.

On one soil type, zinc deficiency is due to a low content of native zinc in this very old, much leached, infertile, quartzitic silty loam. A period of heavy drought, which crippled the rootsystems of the crop brought the hidden zinc shortage into acuteness.

On the other soil type, the low content of zinc is very much accentuated by adverse soil conditions which impair the intake of zinc by the roots. A high $\mathrm{pH}$, very high phosphate level, poor water retaining capacity in dry season and poor aeration of the soil in wet season are regarded to be responsible for soil induced deficiency on this soil type.

An observational field trial with zinc sprays yielded convincing evidence that recovery of sick, deficient trees could be achieved within seven months time.

Photos of experimental trees, zinc deficient branches and leaves, all made by author at the Government Agric. Exp. Station Kota Nica, are produced for illustrative purposes.
\end{abstract}

\section{INTRODUCTION}

Zinc deficiency has been reported from all the citrus growing areas of the world and has also been recorded for several other crops in countries of the temperate and tropic climates.

The soil types involved are rather diverse, including heavy clays, clay loams, light humus sands and peats.

In certain soil types the deficiency is associated with a very low level of total zinc. In some instances this very low zinc level can be attributed to lack of zinc in the original mineral composition of the soil, whilst other soils have lost most of their native zinc through a process of prolonged weathering and extensive leaching.

On other soil types the occurrence of zinc deficiency in crops is rather "soil induced" which means that certain conditions in the soil induce a low availability of zinc to crops. Such conditions may exist in the presence of excessive amounts of calcareous material in the soil, a high $\mathrm{pH}$, a high level of either potash or phosphate, whereas lack of aeration in compact or poorly drained soils may also reduce the availability of zinc and other minor elements to crops. It is obvious that the results of "soil induced deficiency" wil become earlier manifest and more acute in those soil types where native zinc is already low.

The interference of adverse soil conditions with the availability of zinc to crops should not be interpreted merely in terms of soil chemistry e.g. the formation of insoluble zinc compounds in the soil.

The interference is rather of a physiological nature, causing a disturbance of the intake mechanism of ions by the plant roots or, checking the further transport

1) Received for publication September 3, 1959. 


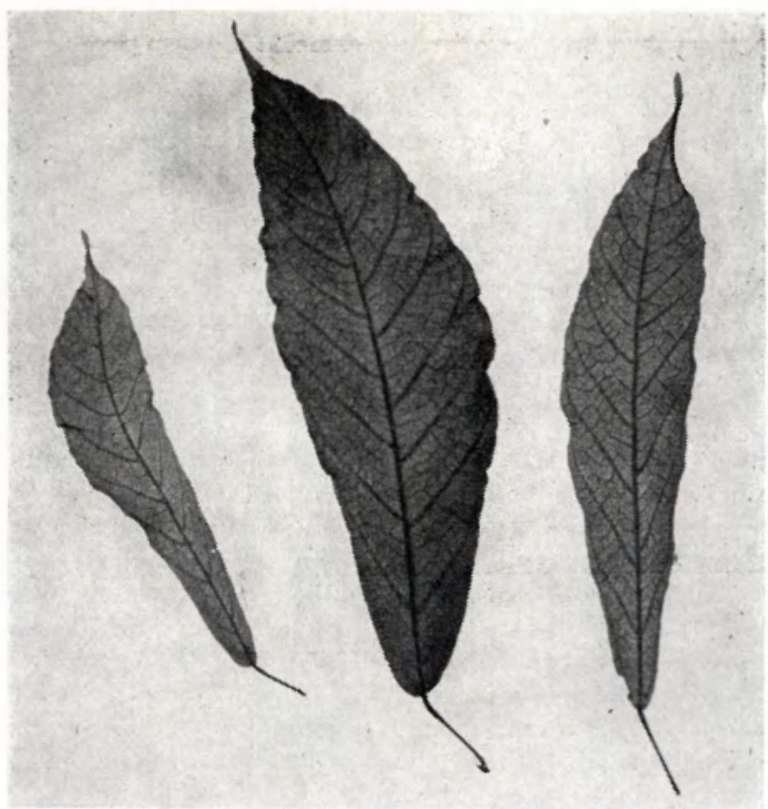

Fig. 1 Cacao leaves showing pronounced symptoms of zinc: deficiency. Lamina show ASYMETRICAL DEVELOPMENT, WAIST NEAR BASE, SLIGHT SICKLE-SHAPE, FLUTED MARGINS aND CharaCteristic VEIN PATTERN.

of absorbed ions inside the plant's system. It is for this reason that various crops differ considerably in their physiological adjustment to soil induced deficiencies.

The selective faculties of plantroots with regards to the intake of ions differ with the type of crop and even with variety.

Another factor of great importance in this respect is the extension and density of various root systems. It is the total area of active root surface partaking in the process of ion-absorption that is more or less specific for any one crop or variety and that is decisive when it comes to the question whether a given nutrient concentration in the soil is adequate or not.

In this respect it can be observed that small plants, young plants and plants with damaged root systems may show deficiency symptoms where others grow healthy on the same soil.

This varying degree of efficiency by which crops utilize available zinc resources of the soil has been clearly demonstrated by VIETs et. al. 1), who experimented with twenty six different crops on zinc deficient soil.

As far as cocoa is concerned, zinc deficiency in the field has been reported by Evans et. al. (2) to occur in a mild way on certain soils in Trinidad during wet seasons.

Greenwood et. al. (3) mentioned iron and zinc deficiency occuring in cacao seedling beds in the Gold Coast.

TollenaAr (4) described the stimulating effect of zinc spraying on the fruitsetting of cacao in Equador. In his case the deficiency was apparently of a mild and hidden nature, as he did not mention the appearance of distinct leaf symptoms. 


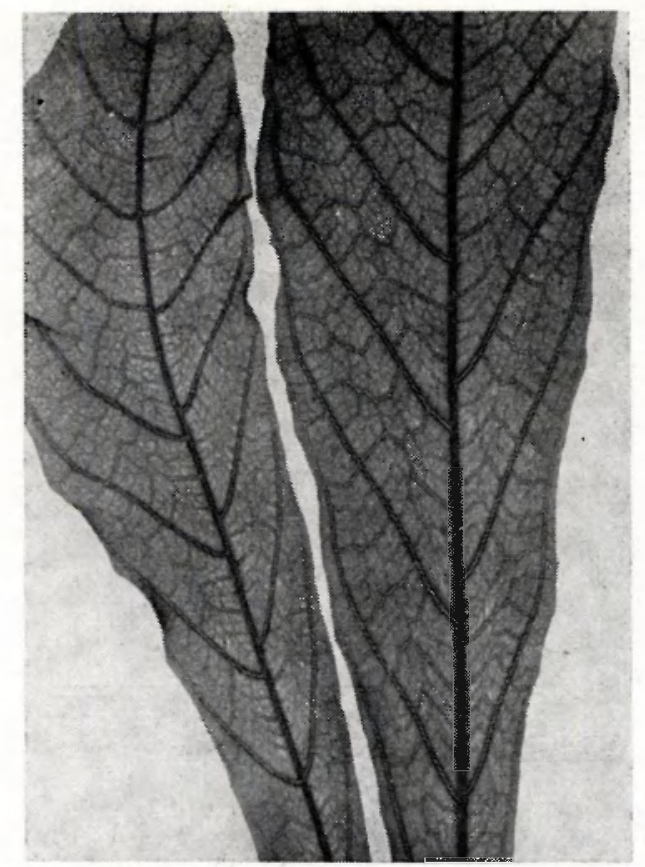

Fig. 2 Close-up of distorted vein pattern and interveinal chloros.

\section{Characteristic leaf symptoms}

The symptoms of zinc deficiency on cacao leaf in various stages of severity have been described very instructively by Evans et. al. (2). This authority may be quoted as follows :

"Zinc deficiency symptoms may be seen in the leaf at a very early stage in its development. The small veinlets are very prominent. When the young leaf ( 1 to 2 inches in length) is held against the light, the sharpness of the minor veinlets differs markedly from those of a normal leaf, where the contrast of the veinlets against the surrounding tissues is very slight. With more severe deficiency the veinlets are distorted much more so towards the base of the leaf (see fig. 1 and 2). The interveinal areas between the distorted veinlets are very pale in colour in the young leaf. On hardening, the prominent vein symptoms and chlorotic areas persist.

In mild deficiency the leaf shows an abnormally high ratio of length to width (see fig. 3) and the chlorotic areas are distinctly associated with the veins, forming symmetrical rows on each side of the midrib and main lateral veins.

With increasing deficiency the width of the deaf decreases progressively, the margin of the leaf is fluted or wavy and the whole leaf may be spirally twisted (see fig. 3).

In the intermediate range of deficiency many of the leaves may show a distinct waist near the base or, may show unequal development of lamina on opposite sides of the midrib, resulting in curved leaves which are sickle-shaped and in addition (may) show the characteristic chlorotic areas.

The sickle-shape (fig. 1) is not so much found in acute deficiency where leaves are small and leaf width is often reduced to $\frac{1 / 2}{2}$ inch, nor in very mild deficiency where leaf may be long and narrow."

It will de appreciated that varying degrees of deficiency may be noted on branches of one single tree, whereas the severety of the deficiency also may alter from year to year. 


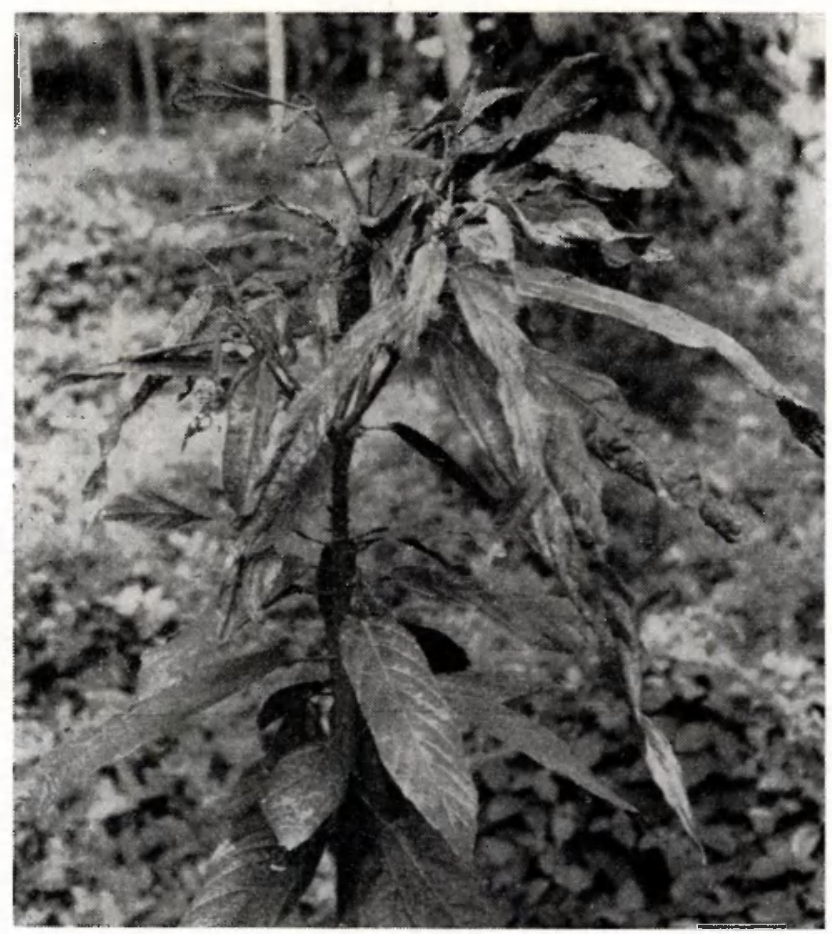

Fig. 3 Badly efFected tree, Showing poOR terminal growth of top and Branches, LONG NARROW, SPIRALLY TWISTED LEAVES.

Once the symtoms have developed and the leaves matured, no regression of these symptoms can be expected as a result of any treatment with zinc. The improvement of conditions will show, however, in the new flush.

In trees suffering from acute deficiency, author noted a premature shedding of the leaves, a die-back of the terminal shoots followed by a repeated branchingoff of the twigs (see fig. 4).

Under such conditions the terminal leaves grow very small and thin, right from the flushing stage onwards. In this respect, the essential features of acute zinc deficiency in cacao resemble those of citrus very much.

\section{Zinc Defictency observed in New GuINeA}

Not until a few years ago, a start has been made with the planting of cacao in Netherlands New Guinea. Cacao trees in this country are therefore young, the oldest of which have come into bearing presently. So far, planting of cacao is done exclusively by native peasants and small holders and is restricted to a number of fairly small centres which ar widely scattered over the vast area of this wild and thinly populated territory.

Accordingly, various soil types are found to be in use for cacao growing. Until now, only on two soil types pronounced leaf symptoms of zinc deficiency have been recognized in the field.

One soil type, represented by soil sample nr. 3690 from Homlikia, is a silty loam of the Mappi district in the South. 


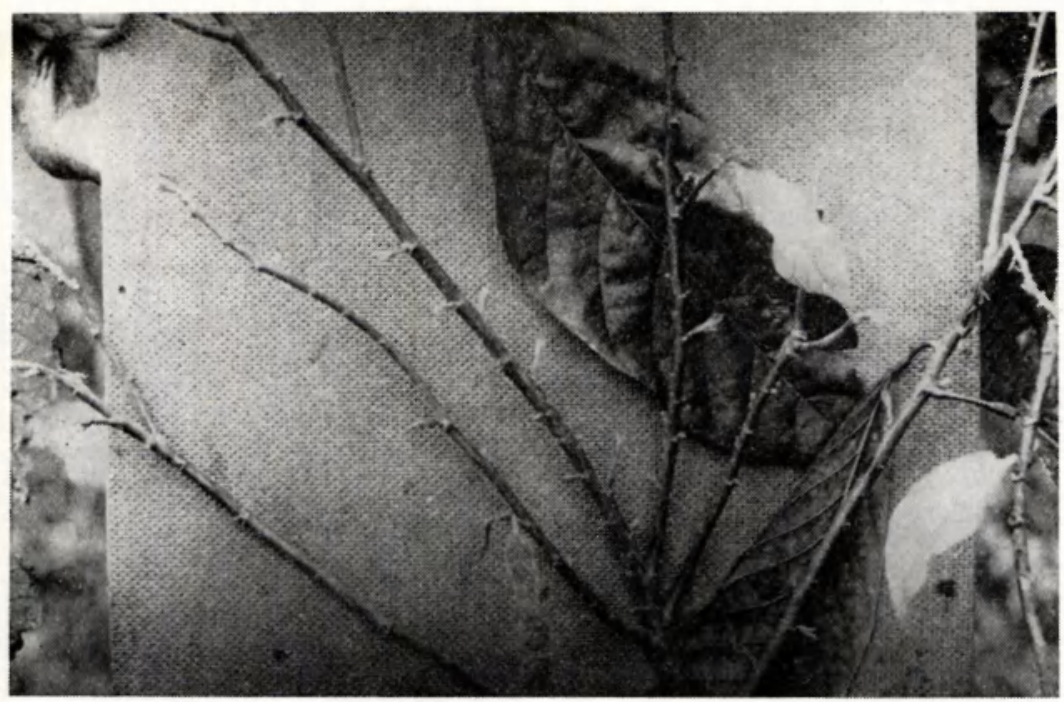

Fig. 4 Completely defoldated BRANCh ShowlNg PRofuse shoot formation.

It is a very old, acid, highly leached infertile soil, mainly composed of quartz grains. The analytical data show very low levels of available calcium and magnesium whereas its available phosphate content is practically zero. This soil is bound to have a very low content of zinc. Fortunately the soil is deep, porous and well drained so that older trees may overcome this zinc shortage in time through the development of a deep and extensive root system.

The leaf symptoms of zinc deficiency appeared in this area very pronouncedly after a heavy drought crippled the rootsystems of the two year old trees. The following year, after plenty of rain, part of the new flush looked healthy, although on many trees mild symptoms of zinc deficiency were still produced in the new flush.

Table 1

\begin{tabular}{|c|c|c|c|c|c|c|c|c|c|c|}
\hline \multirow{2}{*}{$\begin{array}{l}\text { Sample } \\
\text { from }\end{array}$} & \multicolumn{3}{|c|}{ Texture : } & \multicolumn{2}{|c|}{$\begin{array}{c}\mathrm{pH} \\
\text { in }\end{array}$} & \multirow{2}{*}{$\begin{array}{l}C \\
\text { \% }\end{array}$} & \multicolumn{4}{|c|}{$\begin{array}{l}\text { Available nutrients (ppm) } \\
\text { (in } 3 \% \text { acetic acid) (Truog) }\end{array}$} \\
\hline & $\underset{\%}{\operatorname{sand}}$ & $\underset{\mathscr{6}}{\text { silt }}$ & $\underset{\mathscr{q}}{\operatorname{clay}}$ & $\mathrm{H}_{2} \mathrm{O}$ & $\mathrm{KCl}$ & & $\mathrm{CaO}$ & $\mathrm{MgO}$ & $\mathrm{K}_{2} \mathrm{O}$ & $\mathrm{P}_{2} \mathrm{O}_{5}$ \\
\hline $\begin{array}{l}\text { Homlikia } \\
\text { nr. } 3690\end{array}$ & 42 & 51 & 7 & 5,2 & 4,6 & 4,67 & 170 & 20 & 160 & 2 \\
\hline $\begin{array}{l}\text { Kota Nica } \\
\text { nr. } 3124\end{array}$ & 28 & 66 & 6 & 7,0 & 6,2 & 1,60 & 1000 & 1840 & 50 & 250 \\
\hline
\end{tabular}

The other soil type, represented by soil sample nr. 3124 from Kota Nica, is a silty loam which is found on certain alluvial fans at the foot of the Cycloop Mountains in the North.

This alluvial material is composed of minerals mainly derived from mica schists and serpentine laterites. 

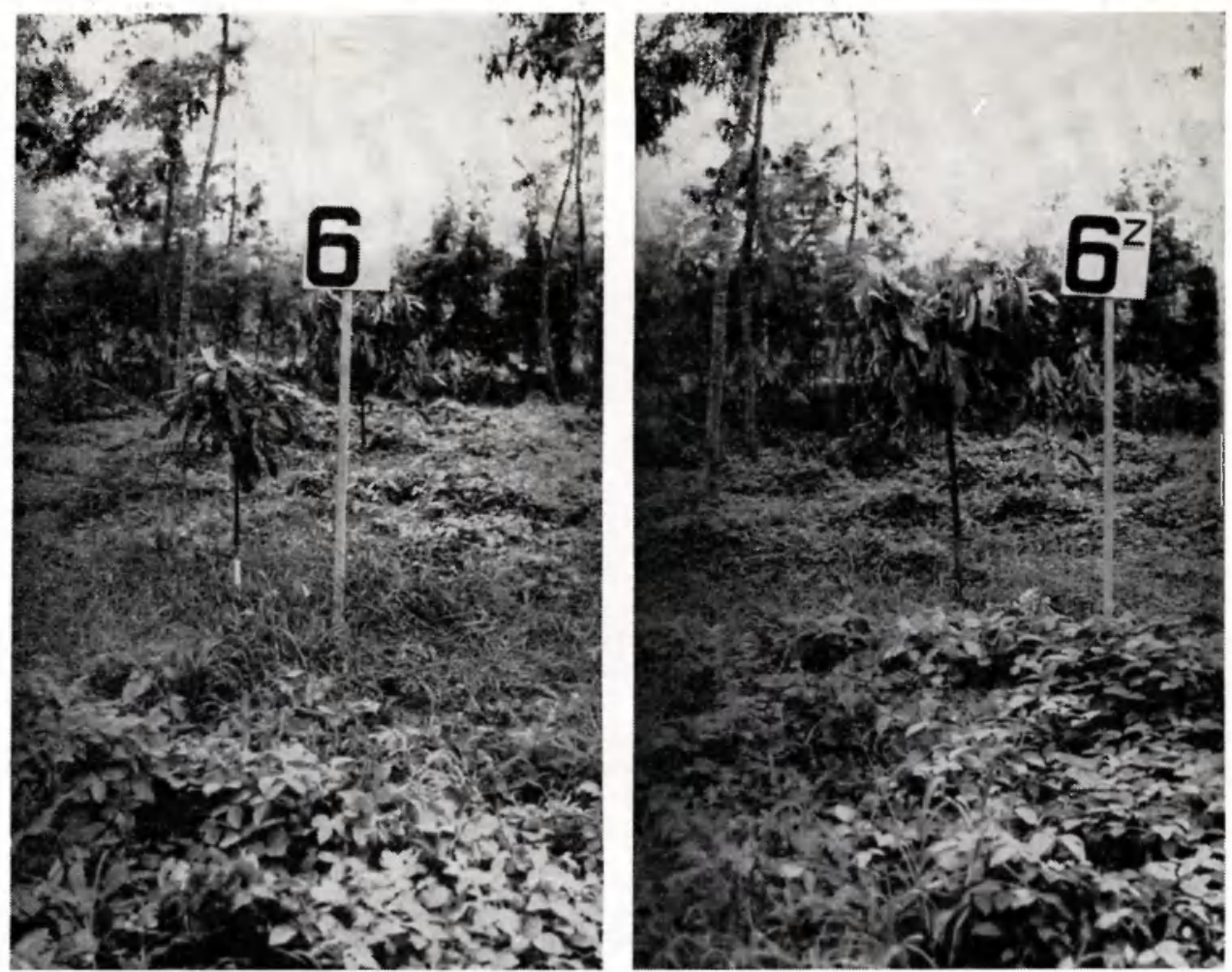

Fig. 5 Paik of trees at the beginning of the spray treatment. ONly tree $6 Z$ will

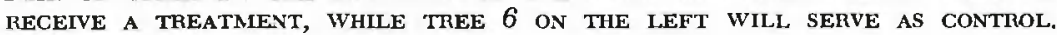

The soil's reaction is neutral to slightly alkaline, due to the presence of magnesium carbonates. In spite of appreciable amounts of micas, available potash is very low in this soil. However, very high values are found for available phosphate, due to the occurrence of the mineral apatite.

At the experimental station, situated on this soil type, distinct leaf symptoms of zinc deficiency were noted on cacao as well as on citrus and rubber. The soil analysis did show a content of $1 \mathrm{ppm} \mathrm{Zn}$, which is considered to be low. (Extraction : $5 \mathrm{gr}$, soil : $200 \mathrm{cc} 2 \frac{1}{2} \%$ acetic acid-16h : determination : dithizon method).

Besides this low content of native zinc, interfering factors such as high $\mathrm{pH}$, very high available $\mathrm{P}_{2} \mathrm{O}_{5}$, poor water holding capacity during dry season and very poor aeration during wet season, undoubtedly accentuate this matural zinc shortage very much.

\section{Observational field trial at Kota Nica}

In a block planted with 4 years old Amelonado cacao, eight pairs of trees were selected in such a way that two selected trees out of each pair were very similair in height, development and degree of zinc deficiency as judged by the appearance of the foliage. All 16 trees were photographed, each from a fixed position and distance. 

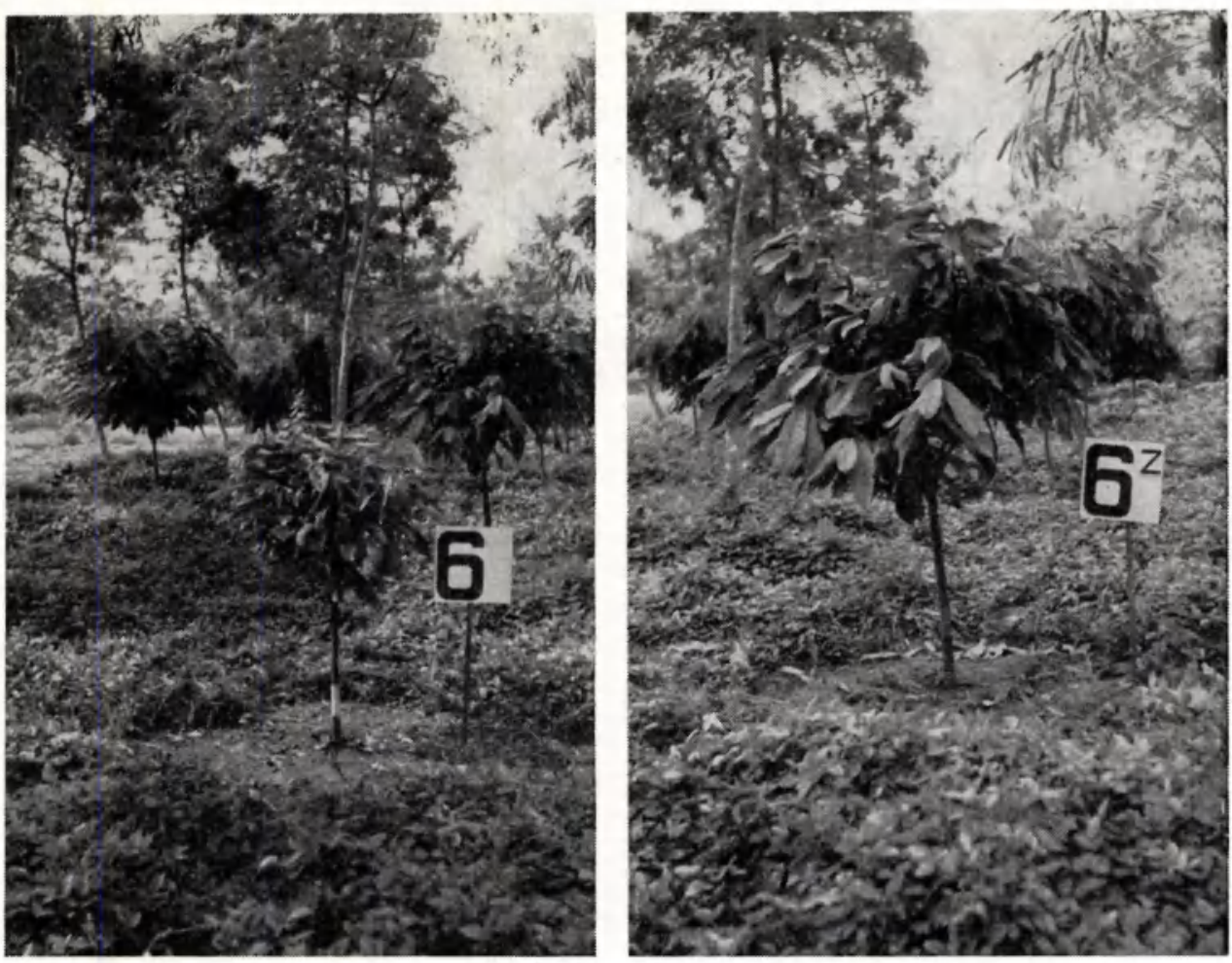

Fig. 6 Same pair of tilees 7 months Later. The Control has remained SickLy aNd MADE haRdLY ANY NEW GROWTH. THE THEATED TREE $6 Z$ has AlMOST COMPLETELY recovered. Here and there old affected leafs are still to be seen.

One tree out of each pair (trees $1 \mathrm{Z}-8 \mathrm{Z}$ ) was sprayed every ten days with zinc sulphate $\left(2 / 2\right.$ gr $\mathrm{ZnSO}_{4} /$ tree) from the 10th of August 1958 onwards until the 10th of March 1959. The other 8 trees ( $1-8)$ remained untreated and served as controls.

At the end of March all 16 trees were photographed again in exactly the same way as was done previously. The observations made and the contrast photos showed clearly that each of the sprayed trees had improved considerably and looked quite healthy, whereas the oontrols were still in very poor shape and still showing pronounced symptoms of zinc deficiency.

The figures 5 en 6 of pair $\mathrm{nr} 6(6=$ untreated, $6 \mathrm{Z}=$ treated $)$ illustrate tris fact convincingly.

As a check, leaf samples of two Zn-deficient trees and leaf samples of two recovered trees were taken one month after the final spray was applied and plenty of rain had fallen.

Each sample consisted of 20 leaves which were the 2nd and 3nd fully grown leaves from 10 branches.

The leaves were carefully cleaned with distilled water and a soft brush in three separate washings so as to remove possible rests of previous zinc sprays. The untreated leaves received the same treatment. After drying, the total $\mathrm{Zn}$ content of the samples was determined: $20 \mathrm{ppm} \mathrm{Zn}$ was found as an average for deficient leaves and $33 \mathrm{ppm} \mathrm{Zn}$ was found in the healthy leaves (ppm = 
$\mathrm{mgr} / \mathrm{kg}$ dry $\mathrm{m}$.). Although the contrast is quite evident, it is not fully appreciated. yet whether the higher lever of $33 \mathrm{ppin} \mathrm{Zn}$ should be regarded as to be a level of adequacy or not. For european fruit trees, a level of $50 \mathrm{ppm} \mathrm{Zn}$ isiassumed to represent an average level of adequadcy.

\section{REFERENCES:}

1 VIETS, F. G. et. al. : Zinc contents and deficiency symptoms of 26 crops grown on a zinc deficient soil. Soil Sc. 1955. Vol. 78.

2 Evans, H. and R. G. Fennah: Investigations on the mineral nutrition of Cacao. "A report on cacao research 1945-1951". I.C.T.A. Trinidad.

3 Greenwood, M. and R. J. Hayfron: Iron and Zinc deficiencies in Cacao in the Gold Coast. Emp. J. Expt. Agric. 9, 73-86 (1951).

4 Tollenank, D.: The stimulating effect of zinc-spray on the fruit setting of cacao. "De Bergcultures" nr. 24, 1957.

5 Bibliography of the literature on the minor elements and their relation to plant and animal nutrition. Chilean Nitrate Educational Bureau. Vol. I-IV. 